\title{
European Council of Legal Medicine (ECLM) accreditation of forensic pathology services in Europe
}

\author{
P. Mangin • F. Bonbled $\cdot$ M. Väli • A. Luna • \\ T. Bajanowski • H. P. Hougen • B. Ludes • D. Ferrara • \\ D. Cusack • E. Keller • N. Vieira
}

Received: 23 June 2014 / Accepted: 24 June 2014 / Published online: 6 July 2014

(C) Springer-Verlag Berlin Heidelberg 2014

\begin{abstract}
Forensic experts play a major role in the legal process as they offer professional expert opinion and evidence within the criminal justice system adjudicating on the innocence or alleged guilt of an accused person. In this respect, medico-legal examination is an essential part of the investigation process, determining in a scientific way the cause(s) and manner of unexpected and/or unnatural death or bringing clinical evidence in case of physical, psychological, or sexual abuse in living people. From a legal perspective, these types of investigation must meet international standards, i.e., it should be independent, effective, and prompt. Ideally, the investigations should be conducted by board-certified experts in forensic medicine, endowed with a solid experience in this field, without any hierarchical relationship with the prosecuting authorities and having access to appropriate facilities in order to provide forensic reports of high quality. In this respect, there is a need for any private or public national or international
\end{abstract}

\section{P. Mangin $(\bowtie)$}

University Center of Legal Medicine, Geneva-Lausanne,

Lausanne, Switzerland

e-mail: patrice.mangin@chuv.ch

\section{F. Bonbled}

Anatomie pathologique médecine légale,

Brussels, Belgium

M. Väli

University of Tartu, Tallinn, Estonia

\section{A. Luna}

University of Murcia, Murcia, Spain

\section{T. Bajanowski}

Institute of Legal Medicine, University Hospital Essen,

Essen, Germany

H. P. Hougen

University of Copenhagen, Copenhagen, Denmark authority including non-governmental organizations seeking experts qualified in forensic medicine to have at disposal a list of specialists working in accordance with high standards of professional performance within forensic pathology services that have been successfully submitted to an official accreditation/certification process using valid and acceptable criteria. To reach this goal, the National Association of Medical Examiners (NAME) has elaborated an accreditation/certification checklist which should be served as decision-making support to assist inspectors appointed to evaluate applicants. In the same spirit than NAME Accreditation Standards, European Council of Legal Medicine (ECLM) board decided to set up an ad hoc working group with the mission to elaborate an accreditation/ certification procedure similar to the NAME's one but taking into account the realities of forensic medicine practices in Europe and restricted to post-mortem investigations. This accreditation process applies to services and not to individual

\section{B. Ludes}

Université Paris-Descartes, Institut Médico-Légal,

Paris, France

D. Ferrara

University of Padova, Padova, Italy

D. Cusack

University College Dublin, Dublin, Ireland

\section{E. Keller}

Department of Forensic and Insurance Medicine, Semmelweis University, Budapest, Hungary

\section{N. Vieira}

Faculdade de Medicina da Universidade de Coimbra, Instituto Nacional de Medicina Legal e Ciências Forenses, Coimbra, Portugal 
practitioners by emphasizing policies and procedures rather than professional performance. In addition, the standards to be complied with should be considered as the minimum standards needed to get the recognition of performing and reliable forensic pathology service.

\section{Keywords Accreditation - European Council of Legal Medicine $\cdot$ Forensic pathology services}

Forensic experts play a major role in the legal process as they offer professional expert opinion and evidence within the criminal justice system adjudicating on the innocence or alleged guilt of an accused person. In this respect, medico-legal examination is an essential part of the investigation process, determining in a scientific way the cause(s) and manner of unexpected and/or unnatural death or bringing clinical evidence in case of physical, psychological, or sexual abuse in living people. Forensic practitioners are also involved in the identification of victims of mass disasters and armed conflicts as well as in the characterization of tortures and any other inhuman or degrading treatment on prisoners or any persons retained in custody whatever the motives.

From a legal perspective, these types of investigation must meet international standards, i.e., it should be independent, effective, and prompt. Ideally, the investigations should be conducted by board-certified experts in forensic medicine, endowed with a solid experience in this field, without any hierarchical relationship with the prosecuting authorities and having access to appropriate facilities in order to provide forensic reports of high quality.

According to its statutes, European Council of Legal Medicine (ECLM) is "the official body dealing with matters relating to legal (forensic) medicine in Europe." As such, ECLM "shall especially pursue the recognition of the discipline and harmonization of practices and quality assurance in the speciality at the European level."

In this respect, ECLM is entrusted with the task to provide to any private or public national or international authority, including non-governmental organizations seeking experts qualified in forensic medicine, a list of specialists working in accordance with high standards of professional performance within European forensic pathology services that have been successfully submitted to an official accreditation/certification process using valid and acceptable criteria. To reach this goal, ECLM board decided to set up an ad hoc working group including Prof. Patrice Mangin (chairman, Switzerland), Prof. Frédéric Bonbled (Belgium), Prof. Marika Väli (Estonia), Prof. Aurelio Luna (Spain), Prof. Thomas Bajanowski (Germany), and Prof. Hans Petter Hougen (Denmark) with the mission to elaborate an accreditation/certification checklist which should be served as decision-making support to assist inspectors appointed by ECLM board to evaluate applicants. Since the National Association of Medical Examiners (NAME) has already elaborated such a checklist $[1,2]$ and in order to not reinvent the wheel, the ECLM board suggested to make use of it as a template taking into account the realities of forensic medicine practices in Europe. NAME gave its agreement through its president Dr. Gregory A. Schmunk. Given the scope covered by the NAME [3] checklist, it was decided to restrict the following checklist to post-mortem investigations.

In the same spirit than NAME Accreditation Standards, this accreditation process applies to services and not to individual practitioners by emphasizing policies and procedures rather than professional performance.

In addition, the standards hereunder developed should be considered as the minimum standards needed to get the recognition of performant and reliable forensic pathology service.

These accreditation standards are compatible and consistent with the Recommendation R(99) 3 of the Council of Europe on the Harmonisation of Medico Legal Autopsy Rules, adopted by the committee of Ministers in February 1999 [4] and recently updated by ECLM.

The document was validated on January 2014 in Dubaï by the ECLM board after consultation of all national delegates from European countries which are part of ECLM.

\section{A. GENERAL}

\section{A.1. FACILITIES}

Y N P

\section{A.1.1.}

Is the service located in a (part of a) building specifically dedicated to forensic and medicolegal investigations?

\section{A.1.2}

Does the service have sufficient space, equipment, and facilities to support the volume of medicolegal death investigations to be carried out?

A.1.3

Is there sufficient general storage space available for the needs of the service?

\section{A.2. SECURITY}

\section{A.2.1}

Is the access to the service controlled?

A.2.2

Are laboratories and autopsy room(s) physically separate from other work areas, and do they have controlled access? A.2.3

Is an after-hours locked storage area or depository available for evidentiary material?

A.3. ADMINISTRATIVE SPACE

A.3.1

Is sufficient office space available for forensic pathologists, administrative and other office staff?

A.3.2

Is each pathologist's office furnished with a desk, shelves, file cabinet, $\mathrm{PC}$ with secure internet access, dictation equipment and access to a microscope? 


\section{A.3.3}

Are facilities available for meeting/conference and training area, library and break/dining area?

A.3.4

Is the administrative area separate from the autopsy room(s), laboratories, and body receiving area so that it is accessible to visitors without visual, auditory, or olfactory exposure to autopsy activity?

A.3.5

Is there a reception area that divides visitors from the rest of the service?

\section{A.4. SAFETY}

A.4.1

Are employees and visitors safe from physical, chemical, electrical, and biologic hazards?

A.4.2

Are safety policies and procedures written and posted or readily accessible?

A.4.3

Are first-aid kits, safety showers, and eye washes located in the laboratories?

A.4.4

Are dedicated and marked specialized safety containers used for disposing of hazardous chemicals and biologic waste that comply with country and local regulations regarding chemical and biological waste disposal?

\section{A.5. MAINTENANCE}

A.5.1

Are the facilities and all work areas clean and well maintained?

A.5.2

Are public access areas comfortable, clean, and free from odour?

A.5.3

Are scientific equipment items that require periodic cleaning, adjustment or maintenance, such as microscopes, freezers and coolers, on a documented and appropriate maintenance schedule?

A.5.4

Are the heating/ventilation/air conditioning, plumbing, and electrical systems of all the facilities scheduled for routine inspection and preventive maintenance?

\section{A.6. MASS DISASTER PLAN}

A.6.1

Does the service have a written and implemented mass disaster (multiple fatalities) plan that includes consideration of protective clothing and equipment, body handling and disposal, and which mandates appropriate preparatory staff training?

A.6.2

Has the service participated in local or regional mass disaster exercises?

A.6.3

Is a communication plan/order contact list of pertinent officials, offices, phone numbers, and e-mail addresses readily available?

A.6.4

Are alternative morgue sites designated?

A.7. QUALITY ASSURANCE

A.7.1

Does the service have a written and implemented policy or standard operating procedure which is reviewed least every two years, covering quality assurance?

A.7.2

Is the quality assurance program sufficient and adequate to assure the quality of the service?
A.7.3

2 Is there documentation of corrective action taken for identified deficiencies?

A.7.4

1 Does the service have a procedural method of keeping track of unfinished or overdue case reports?

A.8. ANNUAL STATISTICAL REPORT

A.8.1

Does the service prepare an annual report including total cases

2 reported, examined, and autopsied as well as the major causes of death?

A.8.2

Does the service perform more than 200 autopsies per year?

1 A.8.3

Does the service perform more than 400 autopsies per year?

B. INVESTIGATIONS

2 B.1. SCENE INVESTIGATIONS

B.1.1

Is a forensic pathologist available on a 24-hour basis to respond

1 for a scene investigation?

B.2 IDENTIFICATION

B.2.1

1 Does the service have a written and implemented policy or standard operating procedure covering identification procedures which is reviewed at least every three years?

B.2.2

Is the method of identification recorded using Interpol post

1 mortem and ante mortem forms?

B.2.3

2 Does the service have access to conduct dental examination?

B.2.4

Does the service have access to conduct radiological

1 examination of the body?

B.2.5

Does the service have access to DNA analysis?

B.2.6

Does the service have access to forensic anthropology?

2 B. 2.7

Is there a method by which family or friends can make visual identification of decedents (viewing room, digital photography, etc..)?

B.2.8

2 Prior to disposition of unidentified bodies, does the service perform the following tasks in order to permit potential future identification: body fingerprinting (if not done by the police); dental examination; radiological examination of the body; collection and storage specimens for DNA?

\section{MORGUE OPERATIONS}

2 C.1 BODY HANDLING

\section{C.1.1}

Do body handling procedures ensure the integrity of evidence

1 by the use of sealed body bags or by other similarly effective means?

C.1.2

Is there a system to document the acquisition, custody,

2 integrity, and release of personal effects?

C.1.3

Is there a written and implemented procedure in place to assure

1 the release of the correct body and personal effects to the funeral home?

C.1.4

Is the body receiving area adequate in size and designed to

2 accommodate the usual volume of incoming and outgoing bodies with safety and security? 
C. 1.5

Are body receiving and handling areas sequestered from public view?

C.1.6

Is access to body receiving and handling areas limited and controlled?

C.1.7

Is refrigerated storage space sufficient to accommodate the number of bodies and their handling during usual and peak loads?

C.1.8

Is the refrigerated storage space easily accessible to the autopsy room and to the body release area?

\section{C.1.9}

Is a separate or functionally isolated room or area available for the storage of decomposed and known infectious bodies?

C. 1.10

Are temperature monitoring devices present on each refrigerator and freezer space; is there an alarm system to warn of deviations from the acceptable range, and are monitoring records kept?

\section{C.2 AUTOPSY ROOM}

\section{C.2.1}

Are private and secure lockers, changing areas, and shower facilities or the equivalent available for employees?

C.2.2

Can the autopsy room accommodate the usual and peak case load including the typical number of autopsies and external examinations, the normal complement of autopsy and laboratory personnel, official participants and observers from cooperating offices?

\section{C.2.3}

Does the ventilation system control odour and fumes and prevent them from entering and leaving the autopsy and body storage areas?

\section{C.2.4}

Do the heating and cooling systems maintain a working environment conducive to effective work performance?

C.2.5

Is the lightning adequate?

C.2.6

Is a body scale located in or near the autopsy room, the body reception, or pre-autopsy preparation area?

\section{C.2.7}

Are sufficient autopsy stations available for the usual case volume?

C.2.8

Is suction available at the autopsy stations?

C.2.9

Are autopsy dissecting sinks equipped with back flow protection devices?

C. 2.10

Is there a stable surface for dissection at each station (either table stand or permanent structure)?

\section{2.11}

Are floor, sink, and table drains able to handle autopsy waste and small particulate matter, with clean-out traps easily accessible?

\section{C.2.12}

Are surfaces for preparation of documents and records far enough removed from the examination areas to avoid inadvertent contamination?

C. 2.13

Are surfaces in the autopsy room nonporous and easily cleaned?

\section{2.14}

1 Is dictation equipment or another means of recording postmortem findings available in the autopsy room, adjacent to the autopsy room, or in pathologists' offices?

1 C. 2.15

Is separate or functionally isolated room or area available for the autopsies of decomposed and known infectious bodies?

1 C. 2.16

Are appropriate personal protective devices including face protection, chest and arm protection, gloves, shoe covers and respirators with filters available to staff so as to reduce

2 biohazard risks?

\section{2.17}

Are standard precautions used when performing autopsies and

2 handling biological specimens?

$$
\text { C.2.18 }
$$

Are autopsy tables and dissection areas disinfected with

1 bactericidal/virucidal solutions on a daily basis if they have been used?

C.2.19

Is appropriate storage space available and secured for decedent effects, evidence recovered during investigations, tissues and evidence recovered from bodies, and specimens held for

$1 \quad$ additional laboratory analysis?

C. 2.20

Is space available for examination of clothing, personal effects

1 and other items or evidence discovered on or about the body with a work area or provision that prevents cross contamination of specimens and provides for effective preservation of each item's integrity?

\section{C.2.21}

Are tissue storage areas ventilated and free of formaldehyde

2 and other unpleasant odours?

C. 2.22

Is there separate and safe storage space for reagent gases, solvents, and chemicals?

2 C.3 RADIOLOGICAL FACILITIES

\section{C.3.1}

Does the service have access to radiological equipment or

1 services?

\section{C.3.2}

1 Does the service have access to imaging technologies including CT scanning and/or MRI?

C.3.3

1 Does the service have access to post-mortem angiography investigation?

C.3.4

2 Are radiographic findings especially in case of CT or MRI imaging technologies submitted to the evaluation of a board certified

2 radiologist with a minimal experience in forensic radiology? C.3.5

Is radiological equipment installed in a convenient location in

1 or near the autopsy room?

C.3.6

Is the radiological equipment shielded in accordance with the

2 radiation safety standards edited by country regulation? C.3.7

Is there a documented program in place to assure that all personnel exposed to X-ray or other radiation sources are

2 monitored for radiation exposure?

C. 3.8

Is radiological equipment operated by qualified personnel? C.3.9

2 Is radiological equipment properly and currently licensed and maintained? 


\section{C.4 POSTMORTEM EXAMINATIONS}

C.4.1

Are the circumstances of death, if known, reviewed prior to autopsy?

C.4.2

Are autopsies carried out as soon as possible in order to prevent any deterioration or alteration of histological and toxicological investigations?

C. 4.3

Does the forensic pathologist personally examine all external aspects of the body in advance of dissection?

C. 4.4

Is a forensic pathologist responsible for the conduct of each post-mortem examination, the diagnoses made, the opinions formed, and any subsequent opinion testimony?

C. 4.5

Are all autopsy ex-situ dissections personally performed by a forensic pathologist or in his presence and close supervision? C. 4.6

Is all assistance rendered by pathology assistants, mortuary technicians, or others without medical training performed in the physical presence of and under the direct supervision of a forensic pathologist?

C.4.7

Are specimens routinely retained for toxicological and histological examination during autopsies?

C.4.8

Is there a written and implemented service policy which defines when radiological examinations or imaging investigations are to be performed?

C. 4.9

Is there written and implemented service policy that defines when ancillary tests or procedures are to be undertaken (e.g., outlining when histological, toxicological, microbiologic, biochemical, genetic, anthropological, and dental specimen collection, testing, or consultation is to be done or sought)?

C. 4.10

Are samples routinely obtained for potential DNA analysis (in case of suspected sexual assaults or for molecular analyses in case of sudden cardiac death)?

\section{C.5 EVIDENCE AND SPECIMEN COLLECTION}

C.5.1

Does the service have a written and implemented policy or standard operating procedure which is reviewed at least every two years, covering evidence, tissue and body fluid specimen collection?

C.5.2

Does the service have a written and implemented policy or standard procedure which is reviewed at least every two years, covering evidence and specimen disposition and destruction?

C.5.3

When collected, are autopsy tissue and fluid specimens individually collected; adequately packaged; properly labelled; appropriately preserved; and archived using a consistent and logical specimen numbering system?

C.5.4

Are specimen containers labelled with unique information allowing its univocal identification; the date collected; the type of contents?

C.5.5

Are specimens collected for microbiological evaluation placed into appropriate transport media or sterile containers and promptly transported to the service laboratory?

\section{C.5.6}

In case of suspected sexual contact is the pubic area lightly

1 combed to obtain loose and foreign hairs, and is native control hairs plucked and packaged separately?

\section{5.7}

1 In case of suspected sexual contact are body orifices swabbed and, when requested, specimen examined for the presence of spermatozoa, the presence of seminal fluid, and DNA?

C.5.8

1 Are DNA specimens retained indefinitely or as long as possible according to local legislation?

\section{C.5.9}

1 Does the service have a written and implemented policy, which is reviewed at least every two years, covering the storage of DNA samples?

\section{C.6 CHAIN OF CUSTODY}

1 C.6.1

Does the service have a written and implemented policy or standard operating procedure to assure the integrity of the

1 chain of custody of evidentiary items?

D. HISTOLOGY

\section{D.1 FACILITY AND PRACTICES}

D.1.1

Does the service have access to histology services?

$1 \quad$ D. 1.2

Is adequate space and equipment provided for tissue cutting and for histological preparation of microscopic slides,

2 including an area for special staining methods?

D.1.3

Are microscopic slides retained indefinitely?

D. 1.4

2 Are paraffin blocks stored in a cool area and retained for at least ten years?

D.1.5

In addition to routine $\mathrm{H} \& \mathrm{E}$ staining, are special staining methods available including immunochemistry?

D.1.6

Does the service have access to a cryostat for rapid diagnosis

$1 \quad$ and for fat stains?

D.1.7

Are microscopic slides prepared, examined, and reported in all autopsy cases where it is feasible?

D.1.8

2 Are formalin-fixed or paraffin-embedded tissues stored for at least one year in cases in which microscopic slides are not prepared?

\section{E. TOXICOLOGY}

\section{E.1 TOXICOLOGICAL LABORATORY}

$1 \quad$ E.1.1

Does the service have access to a forensic toxicology laboratory?

E.1.2

Does the toxicology laboratory have suitable space,

1 equipment, scientific instrumentation, reagents, and supplies to manage the caseload?

E.1.3

Is there an appropriate and safe storage system in place for chemicals and reagents, and is there provision for recognition and proper disposal of outdated and expired items?

\section{E.1.4}

Is there a properly ventilated and maintained fume hood in the laboratory or available to laboratory personnel for handling

1 dangerous or unpleasant samples?

E.1.5

Is the laboratory accredited by an official accrediting agency? 


\section{E.2 TOXICOLOGY PRACTICES}

\section{E.2.1}

Is the toxicology laboratory in compliance with guidelines of the international association of forensic toxicologists (TIAFT) or any other recognized organisation?

E.2.2

Is testing routinely available for ethanol and volatiles; carbon monoxide; major drugs of abuse; major acidic and basic drugs? E.2.3

Are tests performed according to written standard operating procedures?

E.2.4

Does the laboratory participate in external drug proficiency testing for drugs of abuse, and are appropriate corrective actions undertaken and recorded when the results of this testing are outside of compliance limits?

E.2.5

Is there active monitoring of the laboratory for quality assurance, and are corrective actions taken when indicated? E.2.6

Are $80 \%$ of toxicology examinations completed within 90 calendar days of case submission?

E.2.7

Is the laboratory equipped with a computerized information management system (LIMS) with an appropriate security system to prevent intrusion, unauthorized release of information, or unauthorized addition, deletion, or alteration of data?

E.2.8

Is there a system to monitor and track overdue toxicology reports?

\section{E.3 TOXICOLOGISTS}

E.3.1

Does the Chief Toxicologist have formal training and experience in forensic toxicology?

E.3.2

Does the Chief Toxicologist hold a relevant doctoral degree

from an academic institution?

E.3.3

Is the Chief Toxicologist certified by a national or international institution dedicated to forensic toxicology?

\section{E.4 TOXICOLOGY SPECIMENS}

E.4.1

Does the service have a written and implemented policy or standard operating procedure which is reviewed at least every 3years, for the collection of toxicology specimens?

E.4.2

Is peripheral blood rather than central blood used for toxicological analyses whenever possible?

E.4.3

Does the collection specimen for toxicological analysis include at least and whenever possible, 5 of these specimens : blood, urine, gastric contents, hair samples, bile and vitreous humor?

E.4.4

Are specimens for toxicology promptly delivered to the toxicology laboratory or stored in a secure refrigerator or freezer until delivery is effectued?

E.4.5

When toxicology is requested, is the toxicologist made aware of the circumstances surrounding the death and any medications which may have been taken by the decedent? E.4.6

In cases of delayed death in hospitalized victims, does the service attempt to obtain the earliest available specimen from the hospital when appropriate?

\section{E.4.7}

In deaths associated with the possible inhalation of toxic gases,

1 are airway and lung specimens collected and stored in containers suitable for headspace analysis?

E.4.8

Are toxicological specimens retained for at least one year in routine cases except in homicide cases ... storage are submitted to local legislation and five years in homicide cases after completion of the toxicological analyses?

1 F. REPORTS AND RECORD KEEPING F.1 REPORTS AND RECORD KEEPING

F.1.1

1 Does the service have a written and implemented policy or standard operating procedure, which is reviewed at least every three years, covering reports and record keeping?

F.1.2

Is the record storage space secure, with controlled access, to

2 ensure the integrity of the reports?

F.1.3

Are records kept in an orderly fashion for easy retrieval of data?

2 F.1.4

Are records of original observations and derived data retained under the care, custody, and control of the service?

2 F.1.5

Are the run sheets of emergency medical personnel, emergency room records, and hospital charts available to the forensic pathologist in charge of the case?

F.1.6

2 In criminal cases and violent or suspected deaths, does the forensic pathologist have access to and obtain as needed the investigative findings of the police and other investigative office, if any?

$1 \quad$ F.1.7

Is a history of past medical illness and current treatment verified with the attending physician or by review of the

2 decedent's medical and emergency treatment records in applicable cases?

F.1.8

1 Are all paper components of the death investigation in a given case filed in the same place, including police investigation reports, scene reports, body examinations, laboratory reports, consultations, and follow-up information?

$1 \quad$ F.1.9

Are completed records located in a central record storage area?

F.1.10

If long term archival records are stored in a location off

1 premises, are they secure and retrievable?

F.1.11

Do written and implemented guidelines detail the archiving

1 and destruction times for all records?

F.1.12

Does the service have a written and implemented policy or standard method for filing, to include how, where, and which records are stored?

$1 \quad$ F.1.13

Does the service have a computerized information

management system?

F.1.14

1 Where the service records are computerized, are they adequately backed up to prevent loss in case of computer malfunction or failure?

\section{F.2 RELEASE OF INFORMATION}

$1 \quad$ F.2.1

Are copies of official reports available to those individuals having a legitimate right to them? 
F.2.2

Is there a written and implemented procedure regarding distribution of records and information?

F.2.3

Does the service have a written and implemented policy regarding media contact?

\section{F.3 SCENE MEDICOLEGAL INVESTIGATIONS}

F.3.1

Is a written scene investigation report prepared by the service for every scene visited?

F.3.2

Do investigation reports include, as applicable, the history obtained from the police and witnesses; past medical history; circumstantial history? Scene observations; pertinent body findings and notations regarding photographs taken and evidence recovered?

F.3.3

Are photographs or digital images prepared to clarify essential spatial relationships between the body, its environment, and any significant investigative facts such as blood, evidence, weapons/instruments, etc.... where appropriate?

F.3.4

Are significant circumstantial and physical observations noted and recorded regarding the time of death, including the presence, location, and degree of postmortem rigor; the location, fixation, and color of postmortem hypostasis; and the temperature of the body and ambient temperature as well as clothing, environmental and climatic conditions?

\section{F.4 REPORTS OF POSTMORTEM EXAMINATIONS}

\section{F.4.1}

Is a narrative report prepared in every post-mortem examination including external examination, autopsy and identification case? F. 4.2

Are written notes taken for each postmortem examination that, along with review of photographs and other records, could be used as a basis for report generation if dictated tapes become lost or damaged?

F.4.3

Referring to point 4.2 , and in order to prevent any loss of tapes, are every post mortem examination report written as early as possible?

F.4.4

Does the autopsy report include a description of external and internal findings, external and internal evidence of injury, review of the organ systems, listing of diagnoses or summary of case findings, and opinions regarding the cause(s) and manner of death?

F.4.5

Is there written documentation of a physical examination of the decedent's clothed and unclothed body prepared, when applicable, for every decedent whose body is examined? F.4.6

Are clothing and personal effects examined and inventoried in all cases brought into the service for postmortem examination? F.4.7

Are records kept identifying autopsy participants and observers?

F.4.8

Is a written list/catalog of histology sections taken, designating the organ or anatomic site from which the section was obtained, made for each autopsy that includes histology?

F.4.9

Are diagnoses or conclusions provided by microscopic examination (histology) given in an additional report or included in the final autopsy report?
F.4.10

2 When applicable, are toxicological and any additional findings (clinical chemistry,microbiology etc....) included in the final autopsy report?

2 F.4.11

When applicable, are the radiographic findings, and in case of CT or MRI imaging the radiologist's report, included in the final autopsy report?

$1 \quad$ F.4.12

Is the cause(s) of death listed in the autopsy report?

F.4.13

1 Is standardized terminology of recognized disease or pathology nomenclature such as WHO...used for archiving the case?

F.4.14

Does the forensic pathologist in charge of the case sign the autopsy (or external examination, identification) report after it

1 has been transcribed, proofread, and corrected?

F. 4.15

Are $90 \%$ of reports of all postmortem examinations completed within 90 calendar days from the time the body has been brought to the service?

1 F.4.16

Does the service keep a current and up-to-date list of pending cases that includes unsigned and incomplete reports of postmortem examination?

\section{F.5 PHOTOGRAPHIC RECORDS}

F.5.1

Is there a designated staff member responsible for the

inventory, care, and maintenance of the photographic

$1 \quad$ equipment and supplies?

F.5.2

Are photographs taken prior to examination or processing of

1 trace evidence, foreign material, blood patterns, and other items important for determining the cause and manner of death or necessary for medico-legal interpretation or presentation? F.5.3

Is measurement scale included in close-up photographs, with

$1 \quad$ evidence photographs?

F.5.4

Are all photographs labeled and filed in a retrievable manner? F.5.5

1 Are pertinent external and internal findings systematically documented photographically?

F.5.6

Is at least one identification photograph taken of all bodies brought to the service?

F.5.7

1 Is there photographic documentation of pertinent findings in suspected homicides?

F.5.8

Are digital photographs backed up daily, in a location separate

1 from the original, so that a computer failure would not result in permanent loss?

F.5.9

2 Are electronic photograph files copied and stored in at least two locations to prevent loss from a computer malfunction? G. PERSONNEL AND STAFFING

1 G.1 PERSONNEL

G.1.1

Does the service have a written and implemented policy which is reviewed at least every three years, covering personnel issues?

1 G.1.2

Has a copy of the personnel policies been distributed to all personnel? 
G.1.3

Are all potentially exposed or at-risk service staff offered vaccination for Hepatitis $B$, and is such vaccination or refusal to be vaccinated documented?

G.1.4

Is yearly tuberculosis testing offered to at-risk service staff?

G.1.5

Does the service have a written protocol to be applied in case of potential HIV contamination due to a needle or sharp instrument injury?

\section{G.2 PROFESSIONAL STAFF-FORENSIC}

\section{PATHOLOGISTS}

G.2.1

Are all physicians responsible for post-mortem examinations board certified in legal and forensic medicine by the appropriate national or international authority granting such diploma in the country where the service is located?

G.2.2

Are fellows and/or residents working always under the supervision of a board certified forensic pathologist in such a way that any postmortem examination is performed by at least one senior experienced forensic pathologist?

G.2.3

Is the medical staff of sufficient size that no autopsy physician is required to perform more than 250 autopsies/year? (3 external examinations should be considered to be equivalent to one complete autopsy and any significant collateral responsibilities in academic, research, administration etc.... should be taken into account for an appropriate adjustment.)

G.2.4

Are all medical staff members of the service licensed to practice medicine in the country where the service is located? G.3 OTHER PERSONNEL (Technical)

G.3.1

Does the service have written and implemented policies for the qualifications and training necessary for all technical staff (e.g., histotechnologists, mortuary technicians, radiographers, etc.)? G.3.2

Is there sufficient technical staff coverage to handle the routine daily caseload for autopsy and external examination assistance? G.3.3

Is there sufficient technical staff coverage to handle the routine daily caseload for histology?

G.3.4

Is there sufficient technical staff coverage to handle the routine daily caseload for forensic photography?

G.3.5

Is there sufficient technical staff coverage to handle the routine daily caseload for radiological investigation?

G.3.6

Is there sufficient technical staff coverage to handle the routine daily caseload for toxicology?

G.3.7

Is there sufficient technical staff coverage to handle the routine daily caseload for investigations $24 \mathrm{~h} / 7$ ?

G.4 OTHER PERSONNEL (Non-Technical)

G.4.1

Is there sufficient non-technical staff coverage to handle the routine daily caseload for administration?

G.4.2

Is there sufficient non-technical staff coverage to handle the routine daily caseload for visitor reception?

G.4.3

Is there sufficient non-technical staff coverage to handle the routine daily caseload for medical transcription?

\section{G.4.4}

1 Is there sufficient non-technical staff coverage to handle the routine daily caseload for records keeping?

G.4.5

Is there sufficient non-technical staff coverage to handle the routine daily caseload for maintenance and cleaning?

H. SUPPORT SERVICES AND CONSULTANTS

1 H.1 SUPPORT SERVICES

H.1.1

Does the service have laboratory services to perform DNA testing available?

H.1.2

Is DNA testing performed by a laboratory accredited by a

1 recognized organisation to make it at the national level?

H.1.3

Are routine diagnostic clinical chemistry tests available for analysis of post-mortem specimens?

H.1.4

1 Is the clinical chemistry testing performed by a laboratory accredited by a recognized organisation to make it at the national level?

H.1.5

Does the service have microbiology laboratory services available?

H.1.6

Is the microbiology laboratory accredited by a recognized organisation to make it at the national level?

\section{H. 2 CONSULTATIONS}

H.2.1

Does the service arrange for the availability of expert

2 consultants in neuropathology, pedopathology, forensic odontology and radiology, forensic entomology etc....? H.2.2

Are the consultants board certified by the relevant organisations and formally trained in their respective specialties?

$1 \quad$ Application

Each of the questions is designed to induce a "Yes" or "No" response. In addition, each of the questions bears a designation of

2 Priority 1 or Priority 2, respectively. Priority 1 refers to questions specifying standards that are absolutely essential requirements. Priority 2 means that the standards to whom the questions refer are not absolutely essential requirements; in case of deficiency, the quality of the work may not be seriously impacted or the health and safety of the personnel adversely affected.

Full ECLM accreditation means no (0) Priority 1 deficien-

2 cies and no more than one-third Priority 2 deficiencies. Full ECLM accreditation is conferred for a period of 5 years.

Provisional ECLM accreditation means no more than $50 \%$ Priority 1 deficiencies and no more than two-third Priority 2 deficiencies. Provisional ECLM accreditation is conferred for a period of 3 years and may be extended for up to a maximum of three additional years.

In practice, the procedure for any service wishing to be accredited will be as follows:

1. Application must be sent to the President of ECLM along with the documentation needed for a brief assessment of the validity of the request. 
2. The President appoints at least two inspectors from the community of specialists in forensic and legal medicine to investigate the request.

3. The inspectors check and confirm the validity of the request on the basis of the documentation provided by the service at least 1 month in advance of the date of their visit.

4. During the visit to the service, the inspectors proceed to evaluation using the above-mentioned checklist.

5. The inspectors prepare a report for the President of ECLM with a recommendation regarding the request.

6. The President submits the report and the conclusions to the ECLM Board for confirmation or rejection.

7. The final decision is communicated to the service by the President of ECLM.
Acknowledgments The authors and the ECLM board members express their thanks to the officers of NAME and especially to Gregory A. Schmunk and Gregory George Davis for their agreement to let them use the NAME accreditation checklist as template for the ECLM version.

\section{References}

1. National Association of Medical Examiners (2014) NAME Inspection and Accreditation Checklist for Autopsy Services, 1-30

2. Brinkmann B (1999) Harmonisation of medico-legal autopsy rules. Int J Legal Med 113:1-14

3. National Association of Medical Examiners (2014) Inspection and Accreditation Policies and Procedures Manual. NAME Policies and Procedures Manual, 1-22

4. National Association of Medical Examiners (2014) NAME Inspection and Accreditation Checklist, 1-32 